\title{
War Exposure and Maternal Reactions in the Psychological Adjustment of Children from Bosnia-Hercegovina
}

\author{
Patrick Smith, Sean Perrin, William Yule, and Sophia Rabe-Hesketh \\ Institute of Psychiatry, London, U.K.
}

\begin{abstract}
As part of a UNICEF-sponsored Psychosocial Programme in Bosnia, data were collected from a representative sample of 339 children aged 9-14 years, their mothers, and their teachers in order to investigate risk and moderating factors in children's psychological reactions to war. Self-report data from children revealed high levels of post-traumatic stress symptoms and grief reactions, but normal levels of depression and anxiety. Mothers' selfreports also indicated high levels of post-traumatic stress reactions, but normal levels of depression and anxiety. Child distress was related to both their level of exposure and to maternal reactions. Structural equation modeling was used to quantify the relationships between these risk factors and child distress, and to examine putative pathways to account for the association between child and maternal health. Children's adjustment was associated significantly with both exposure $(\phi=.37)$ and maternal mental health $(\phi=.37)$. Modeling also revealed a significant distorting effect of mother's own mental health on behavioural ratings of her child $(\psi=.59)$. Although evidence exists for an association between maternal mental health and mother rating errors, there is also a substantive association between maternal mental health and children's adjustment following war.
\end{abstract}

Keywords: Anxiety, depression, parent-child interaction, post-traumatic stress disorder, war.

Abbreviations: BDI: Beck Depression Inventory; DSRS: Birleson Depression Self-Rating Scale; GHQ: General Health Questionnaire; NFI: Normed Fit Index; PTSD: posttraumatic stress disorder; RCMAS: Revised Children's Manifest Anxiety Scale; RIES: Revised Impact of Event Scale; STAI: State Trait Anxiety Inventory; WTQ: War Trauma Questionnaire.

\section{Introduction}

The investigation of children's psychological reactions to living through war and political violence has shown a steady increase over the last decade or so (Cairns, 1996). Numerous studies, from differing cultures in different war zones around the world, have documented the effect on children of exposure to war atrocities (e.g. Dyregrov \& Raundalen, 1992; Gupta, Dyregrov, Gjestad, \& Mukanoheli, 1996; Kinzie, Sack, Angell, \& Clarke, 1989; Kuterovac, Dyregrov, \& Stuvland, 1994; Macksoud \& Aber, 1996; Nader, Pynoos, Fairbanks, Al-Ajeel, \& AlAsfour, 1993; Richman, Ratilal, \& Aly, 1989; Saigh, 1991). The emerging consensus in the literature is that children show high levels of post-traumatic stress reactions after such experiences. Other outcomes have been studied less thoroughly, but there is also some evidence for an increase in rates of depression and anxiety among child survivors of war (e.g. Chimienti, Nasr, \& Khalifehi, 1989; Mghir, Freed, Raskin, \& Katon, 1995; Zivcic, 1993).

Less attention has been paid to the multiple risk factors

Requests for reprints to: Dr Patrick Smith, Department of Psychology, Institute of Psychiatry, De Crespigny Park, Denmark Hill, London SE5 8AF, U.K.

(E-mail: p.smith@iop.kcl.ac.uk). that produce negative outcomes in children following war. The obvious candidate in explaining children's reactions is their level of exposure to war trauma. Unlike one-off traumatic exposure in peacetime, traumatic stressors in war are commonly multiple, diverse, chronic, and repeated, so it can become difficult to disentangle effects. Nevertheless, several studies (e.g. Chimienti et al., 1989; Kuterovac et al., 1994; Macksoud, 1992; Mghir et al., 1995; Nader et al., 1993) have now confirmed that there is a positive and significant relationship between exposure and outcome in children, usually with respect to posttraumatic stress disorder (PTSD), but also in relation to depression and anxiety. Both the amount and type of exposure are important. For example, after the Gulf War, Dyregrov and Raundalen (1992) found that exposure to dead bodies and body parts was the best predictor of PTSD intrusion symptoms. These authors suggest that exposure to very strong sensory impressions (e.g. smelling burning bodies, hearing screams for help) may result in more severe re-experiencing symptoms. In Rwanda, Gupta et al. (1996) found that the best exposure predictor of child outcome was a (perceived) direct life threat. This is in line with work from elsewhere (e.g. Carlson \& Rosser-Hogan, 1994, with adult Pol Pot survivors; and Nader et al., 1993, with Kuwaiti children), suggesting that threat to survival may be related to post-traumatic stress symptoms across different cultures.

Far less studied has been the influence of maternal reactions on child distress. Bryce, Walker, Ghorayeb, and 
Kanj (1989) found that among 5- to 7-year-old Lebanese children who lived through the war in Beirut, the most important predictor of reports of child morbidity was mothers' level of depressive symptomatology. In a similar vein, in their work with families from the Crossroads squatter camp in South Africa, Dawes, Tredoux, and Feinstein (1989) found that children with multiple symptom presentation were more likely to have mothers who were suffering from PTSD, implying that mothers' mental health is a significant mediator of their children's mental health in times of conflict. These results are consistent with those of McFarlane (1987a, b), who examined family reactions in relation to children's distress following peacetime trauma. Studying families after the Australian bushfires, he found that parents' adjustment was a more important determinant of the adjustment of their children than exposure: families who found it difficult to share their immediate reactions had more trouble with longterm adjustment. Equally importantly, the child's reaction to the fires affected the family's adjustment, suggesting reciprocal interactions among family members. In all three studies, however, independent assessment of the child was not obtained, raising the possibility that mothers' assessment of their children is affected by their own mental health (cf. Boyle \& Pickles, 1997).

The aim of the present study is to investigate the influence of war exposure and maternal mental health on the psychological adjustment of children. An advantage of this study is that independent self-reports of child distress were obtained. In addition, mothers reported on their own psychological health, as well as rating their children's adjustment. Obtaining independent measures in this way allowed the relative importance of the interacting influences of child exposure and maternal mental health on child outcome to be estimated. It was predicted that: (1) child exposure and distress across a broad band of measures would be high, and that distress would be associated with exposure; (2) child distress would also be associated with maternal mental health after controlling for the effects of exposure; and (3) mothers' ratings of their child would be influenced by their own psychological health.

Current data were collected as part of a large epidemiological screening survey for a United Nations Children's Fund (UNICEF) psychosocial programme for children in Mostar, Bosnia-Hercegovina, details of which have been reported elsewhere (Hacam, Smith, Yule, \& Perrin, 1998; Smith, Perrin, Yule, Hacam, \& Stuvland, 2000). Briefly, children in Mostar survived over 3 years of war, and the population from the Eastern part of the town was besieged for 9 months, cut off from any international military or humanitarian aid. During the long siege, including a bitter winter, many families in East Mostar lived in basements to shelter from the artillery and sniper fire. It is estimated that more than 100,000 shells landed on the town during the war, that over half of the buildings on the Eastern side of town were damaged or destroyed, and that more than 1500 civilians were killed (UNICEF, 1994). Data collection was carried out at the beginning of 1996 (2 years after the signing of the "Washington Agreement", which brought a semblance of peace of the area) as an integral part of a service-oriented project, in order to identify vulnerable children and to guide service planning. The present paper addresses risk and mediating factors in more detail, reporting on additional data from the mothers and teachers of a stratified subsample of index children from the main epidemiological screening.
Methods

\section{Sample}

Participants were a stratified subsample of children from an epidemiological screening, and their mothers and teachers. The main epidemiological screening comprised 2976 children between the ages of 9 and 14 from all primary schools $(N=10)$ in Mostar and the surrounding area. This represented $84 \%$ of all 9- to 14-year-old children in the region. From the child population, a 1 in 10 sampling was used to give a sample of index children for whom information was also obtained from their mother and teacher. So that fewer teachers needed to be trained in observational ratings and to maximise the likelihood of a good return rate from schools, sampling was by class, and one class in each year in each school was chosen at random. Index children were identified by selecting every $n$th child from an alphabetical class list, where $n=$ class size/number of children required. The mother and teacher of each selected child were asked to participate. Excellent return rates $(84 \%)$ from mothers resulted in self-report data from 339 mothers, and behavioural ratings of their children from 336 mothers. Return rates from teachers were also good $(72 \%)$, resulting in 288 behavioural ratings from teachers of the same children.

\section{Materials}

Bosnian language versions of all English language measures were used, final versions being obtained through translation and blind back-translation (Bracken \& Barona, 1991).

Children's self-report questionnaires.

(1) War Trauma Questionnaire (WTQ; Macksoud, 1992). Originally developed by Macksoud for use in Lebanon, this scale was adapted for use throughout Bosnia-Hercegovina by UNICEF. It includes 28 yes/no questions about events the child may have witnessed during the war. The total score (range 0-28) therefore gives an indication of the child's level of traumatic exposure.

(2) Revised Impact of Events Scale (RIES; Dyregrov \& Yule, 1995): 13 items. The RIES was adapted from Horowitz, Wilner, and Alvarez's (1979) Impact of Event Scale. It is a selfreport scale designed to measure symptoms of intrusion (4 items), avoidance (4 items), and arousal (5 items). A score of $\geqslant 17$ on the 8 items relating to intrusion and avoidance has been found to be an efficient cutoff for PTSD (Dyregrov \& Yule, 1995; Yule, 1998). Using this cutoff, the scale works efficiently at discriminating cases, with both specificity and sensitivity at $90 \%$.

(3) Birleson Depression Self-Rating Scale (DSRS; Birleson, 1981). This 18-item scale assesses the extent of depressive feelings of children and adolescents, and is scored on a 3-point scale (with 8 items reversed for scoring). Good internal consistency has been reported (Birleson, 1981), and the scale is moderately efficient at discriminating depressed from nondepressed children, with specificity of between $77 \%$ and $88 \%$, and sensitivity of between $64 \%$ and $67 \%$ being reported among British children (Asarnow \& Carlson, 1985; Birleson, Hudson, Buchanan, \& Wolff, 1987).

(4) Revised Children's Manifest Anxiety Scale (RCMAS; Reynolds \& Richmond, 1978). The RCMAS is designed to measure generalised nonspecific anxiety in children. The scale comprises 37 true/false items: 28 anxiety items and 9 lie (or social conformity) scale items. Items have good face validity and the scale has shown good internal consistency (James, Reynolds, \& Dunbar, 1994). Concurrent validity indicators are good, with a correlation of .85 with the a-Trait scale of the State Trait Anxiety Inventory for Children (Spielberger, Gorsuch, Luschene, Vagg, \& Jacobs, 1983) reported by Reynolds (1980).

(5) Brief Grief Questionnaire (Nader et al., 1993). This short 9-item questionnaire was developed from a semistructured interview format described by Nader et al. (1993). Items are scored Yes $=1$, No $=0$, with item 9 reversed. In their study of children in Kuwait following the Gulf War, Nader et al. found that $98 \%$ of children endorsed at least one item, with the 
average endorsement being four of the nine items. This questionnaire has not been systematically applied to children bereaved in peacetime and should therefore be regarded as a research tool at present.

Mothers' self-report.

(1) RIES (Dyregrov \& Yule, 1995)-13 items. Mothers completed the same 13-item version of the RIES as their children, which was adapted from Horowitz et al.'s (1979) Impact of Event Scale.

(2) Beck Depression Inventory (BDI; Beck, Rush, Shaw, \& Emery, 1979). This 21-item inventory measures the severity of depression in adults. It is widely used in clinical practice, and for detecting possible depression in normal populations. Each item is scored on a 4-point scale $(0,1,2,3)$ with no reversed items. Good internal consistency has been reported (Cronbach's alpha of .81; Beck, Steer, \& Garbin, 1988). Discriminant validity is also good, and although the inventory was originally developed to measure the depth or intensity of depression in psychiatric patients, a number of studies have reported that the BDI can differentiate psychiatric patients from normals (e.g. Beck et al., 1988).

(3) State Trait Anxiety Inventory (STAI; Spielberger et al., 1983). The State Anxiety section of the STAI is a 20-item scale rated on a 4-point scale. Widely used in research and clinical practice, internal consistency of the STAI is generally good, with Cronbach's alpha coefficients ranging from .86 to .95 (Spielberger et al., 1983).

(4) General Health Questionnaire (GHQ-28; Goldberg \& Hillier, 1979). The GHQ-28 is a 28 -item self-report questionnaire designed to detect psychiatric disorder among respondents in community settings and nonpsychiatric clinical settings. It is divided into four sections that assess somatic symptoms, anxiety/insomnia, social dysfunction, and severe depression. Each item is rated on a 4-point scale (scored 0, 0,1,1). Good internal consistency has been reported in a number of studies, with Cronbach's alpha coefficients ranging from .82 to .90 (Goldberg \& Williams, 1988). For community samples, the most efficient caseness threshold is $4 / 5$ (Goldberg \& Hillier, 1979). Goldberg and Williams review a number of studies where sensitivity ranges from $44 \%$ to $100 \%$ and specificity from $74 \%$ to $93 \%$.

Adult behavioural ratings of children.

(1) Mothers: General Health and Behaviour Questionnaire (Goodman, 1994). This modified version of the Rutter Parent Questionnaire (Rutter A2) (Rutter, 1967; Rutter, Tizard, \& Whitmore, 1970) comprises the original 31 Rutter A2 items, plus 19 new items, 14 of which are prosocial items. Each item is scored on a 3-point scale. Goodman (1994) reports that the internal consistency of the new prosocial scale was good, with Cronbach's alpha of .82. Caseness ratings had sensitivity of $71 \%$ and specificity of $70 \%$ with a threshold score of 13 or more.

(2) Teachers: Strengths and Needs Questionnaire (Goodman, 1994). This modified version of the Rutter Teacher Questionnaire (Rutter B2) (Rutter, 1967; Rutter et al., 1970) contains the original 26 Rutter items, plus 20 new prosocial items. For the prosocial scale, Goodman (1994) reports Cronbach's alpha coefficient of .92. The original B2 scale was efficient at discriminating cases when a threshold score of 9 was used (Rutter, 1967).

\section{Procedure}

For the child self-report questionnaires, data collection was via schools. Teachers were trained to administer the questionnaires by class. Teachers were given letters asking for informed consent from parents, and these were given to every child in the relevant grade. One week later, the questionnaires were delivered to schools and administered by class, except to those children whose parents had refused. Questionnaires were collected from schools on the same day. For the mother data, names of selected children were given to the teachers, along with numbered questionnaires for parents. Children took home an information letter and the parent questionnaires in an envelope. Parents were asked to place their forms in the envelope, seal it, and return it to school via their child. For the teacher ratings, project workers visited schools to train teachers how to use behavioural rating scales, and teachers were asked to complete scales for the same named children.

\section{Analysis}

In a first set of analyses, descriptive data for children and mothers are reported, and the association between child distress, exposure, and maternal distress is explored using simple correlations. Multiple regression analyses are then carried out to examine in more detail the predictors of separate measures of child distress. These analyses were carried out using the Statistical Package for Social Sciences (SPSS, 1993). In a second set of analyses, structural equation modelling (EQS; Bentler, 1989 ) is used to examine measurement issues and risk and mediating factors. For structural equation modelling, missing data were imputed using best subset regression.

\section{Results}

\section{Child Self-reports of Exposure and Adjustment}

Children reported high levels of exposure to war stressors (WTQ $\bar{X}=13.03, S D=4.16$ ). Children's selfreports of post-traumatic stress symptoms were also high (RIES, Total $\overline{\mathrm{X}}=27.09, S D=13.60$ ), with the group mean score on the 8 item total $(\overline{\mathrm{X}}=18.68, S D=9.71)$ exceeding cutoff for likely diagnosis. Grief symptoms were also high (Brief Grief Scale Total $\bar{X}=3.92, S D=$ 1.96), and comparable to those of a group of children who lived through the Gulf War (Nader et al., 1993). Children's self-reported levels of depression (DSRS $\bar{X}=$ $9.40, S D=5.03$ ) were marginally elevated compared to British normative data $(\overline{\mathrm{X}}=8.53, S D=4.43$, Yule, 1998; $t=2.18, p<.001)$, but lower than those of a group of school children who survived a shipping accident $(\overline{\mathrm{X}}=$ 11.11, $S D=5.98$, Yule et al. 1990; $t=4.28, p<.001)$. Children's self-reported anxiety levels (RCMAS $\overline{\mathrm{X}}=$ 10.93, $S D=6.20$ ) were not raised, being lower than American normative data $(\overline{\mathrm{X}}=13.84, \quad S D=5.79$, Reynolds \& Richmond, 1978).

\section{Adult Ratings of Child Adjustment}

Scores on the Rutter-Goodman behavioural rating scales indicated raised levels of disturbance overall among children (teacher-rated total deviance $\overline{\mathrm{X}}=5.19, S D=$ 5.78; mother-rated total deviance $\overline{\mathrm{X}}=7.95, S D=6.05)$. Taking a cutoff of 13 or more, $22 \%(N=72)$ children were identified as cases by mothers (39 emotional, 22 conduct, 11 mixed disorder). Taking a cutoff of 9 or more for teacher ratings, $18 \%(N=52)$ children were identified as cases (31 conduct, 15 emotional, 6 mixed).

\section{Mother Self-reports of Psychological Health}

Mothers' own self-reported levels of post-traumatic stress symptoms were also elevated (RIES Total $\overline{\mathrm{X}}=$ $25.40, S D=15.40$ ), with mean scores on the 8-item total $(\overline{\mathrm{X}}=16.99, S D=10.78)$ approaching the cutoff for likely diagnosis. Mothers' self-ratings of anxiety were marginally elevated (STAI $\bar{X}=38.05, S D=12.06)$ compared to Spielberger et al.'s (1983) normative data for American women $(\overline{\mathrm{X}}=35.21, S D=10.61 ; t=3.45, \quad p<.001)$. Mothers' self-reports of depression were not elevated: the overall mean on the BDI $(\overline{\mathrm{X}}=7.73, S D=8.90)$ was 
Table 1

Pearson Correlation Coefficients between Mother and Child Self-report

\begin{tabular}{|c|c|c|c|c|c|c|c|}
\hline \multirow[b]{2}{*}{ Child self-report } & \multicolumn{7}{|c|}{ Mothers' self-report } \\
\hline & $\begin{array}{l}\text { Total } \\
\text { RIES }\end{array}$ & Intrusion & Avoidance & Arousal & BDI & STAI & GHQ \\
\hline Total RIES & $.33^{* *}$ & $.27 * *$ & $.23 * *$ & $.30 * *$ & $.17^{*}$ & $.24 * *$ & $.19^{*}$ \\
\hline Intrusion & $.33^{* *}$ & $.32 * *$ & $.20 *$ & $.30 * *$ & $.22 * *$ & $.25^{* *}$ & $.24 * *$ \\
\hline Avoidance & $.19^{*}$ & .08 & $.23^{* *}$ & .12 & .02 & .14 & .05 \\
\hline Arousal & $.28 * *$ & $.25 * *$ & .12 & $.30 * *$ & .15 & $.19^{*}$ & $.18^{*}$ \\
\hline DSRS & $.26^{* *}$ & $.27 * *$ & .09 & $.30 * *$ & $.29 * *$ & $.23 * *$ & $.24 * *$ \\
\hline RCMAS & $.23^{* *}$ & $.24 * *$ & .09 & $.27 * *$ & $.17 *$ & $.21 * *$ & .15 \\
\hline Brief Grief Scale & $.24 * *$ & $.26 * *$ & .08 & $.25 * *$ & $.28 * *$ & $.28 * *$ & $.22 * *$ \\
\hline
\end{tabular}

$* p<.01 ; * * p<.001$.

below the cutoff for mild depression that is generally used in clinical practice; and the distribution of scores was highly skewed, with most respondents $(N=216,69.7 \%)$ falling in the normal range, $53(17.1 \%)$ falling in the mild-moderate range, $30(9.7 \%)$ in the moderate-severe range; and $11(3.5 \%)$ in the extremely severe range. Scores on the GHQ were also marginally elevated (GHQ $\overline{\mathrm{X}}=3.62, S D=5.42$ ), with the distribution being highly left-skewed. Threshold scores of $4 / 5$ (Goldberg \& Williams, 1988) indicated that $27 \%$ of mothers $(N=88)$ would be likely cases.

\section{Association between Child Distress and Traumatic Exposure}

Children's self-reported distress was significantly related to their self-reported level of exposure to traumatic war experiences. Exposure was correlated with RIES total scores $(r=.28, p<.001)$, DSRS scores $(r=.18$, $p<.01)$, RCMAS scores $(r=.28, p<.001)$, and scores on the Brief Grief Index $(r=.24, p<.001)$. Exposure was most strongly related to intrusion symptoms $(r=$ $.36, p<.001)$, but not to the avoidance scores from the RIES ( $r=.01$, n.s.).

\section{Association between Child Distress and Maternal Distress}

Child distress was also positively correlated with mother distress (see Table 1). Mothers' and children's RIES scores are positively correlated $(r=.33, p<.001)$, as are mother and child self-reports of depression $(r=$ $.29, p<.001)$. Scores are also intercorrelated, so that mothers' PTSD scores are also associated with child depression and anxiety. The exception is the avoidance subscale of the RIES, which is not significantly correlated with other forms of distress for either mothers or children. Mothers' and children's avoidance scores are significantly associated with each other $(r=.23, p<.001)$.

\section{Combined Effects of Exposure and Maternal Distress on Child Adjustment}

To examine the combined effect of exposure and maternal mental health on child self-reported distress, a series of linear regression analyses were carried out. For each measure of child distress, the child's total exposure, age, gender, and the six measures of mother's psychological health were entered into a stepwise selection procedure. An interaction term (exposure $\times$ gender) was entered to check for differential effects of exposure on boys and girls, but this was nonsignificant in all cases. Only significant explanatory terms are listed below (see Table 2).

For all four measures of child distress, there is a significant effect of exposure and maternal distress, but the amount of variance accounted for overall is relatively modest $\left(\mathrm{R}^{2} \leqslant .26\right)$. Relative to other explanatory variables, exposure is the best predictor of total posttraumatic stress symptoms $(\beta=.28, p<.001)$, intrusion symptoms $(\beta=.36, p<.001)$, and anxiety symptoms $(\beta=.28, p<.001)$. After controlling for exposure, there is a smaller but significant effect of mothers' psychological health on these measures of child distress. In contrast, the best predictor of child depression is mother's psychological health, in particular, her intrusion $(\beta=.18$, $p<.005)$ and depression symptoms $(\beta=.16, p<.05)$. After controlling for mother's mental health, there is a small but significant association between child exposure and depression. Little of the variance in child avoidance scores is explained, but mother and child avoidance scores are significantly associated.

\section{Structural Equation Modelling}

In a final set of analyses, structural equation modelling was used to examine the simultaneous effects of exposure and mother distress on child distress while at the same time quantifying and controlling for the effect of mothers' own distress on the ratings of their children. Structural equation modelling combines path analysis, factor analysis, and linear regression (Bentler, 1989; Fergusson, 1997; King \& King, 1997). For the current data, a measurement model was specified by linking latent variables to observed indicators using factor analysis models. Structural models were then specified by representing the relationship between the latent variables as a system of simultaneous linear equations. These statistical models were then fitted to the observed data (represented by the matrix of variances and covariances of the observed variables), and the goodness of fit between the observed covariance matrix and that implied by the model was calculated. Under the null hypothesis that the observed covariances are of the form predicted by the model, the discrepancy function has a chi-squared distribution. The chi-squared statistic is therefore small and nonsignificant when the model provides a good fit. Since even small discrepancies become significant for large samples, the normed fit index (NFI), which provides a measure of fit that is independent of sample size, is also given. The NFI has an upper limit of unity and needs to take a value of 
Table 2

Multiple Linear Regression: Exposure and Maternal Mental Health on RIES, DSRS, RCMAS, and Brief Grief Scale

\begin{tabular}{|c|c|c|c|c|c|c|c|}
\hline & B & $\mathrm{SE}(\mathrm{B})$ & $\beta$ & $F$ & $\operatorname{sig} F$ & $\mathrm{R}^{2} \Delta$ & $\mathrm{R}^{2}$ \\
\hline \multicolumn{8}{|l|}{ RIES Total } \\
\hline Child exposure & .93 & .19 & .28 & 24.16 & $<.001$ & .10 & .10 \\
\hline Mother intrusion & .40 & .15 & .16 & 7.16 & $<.01$ & .05 & .15 \\
\hline Gender & -5.89 & 1.55 & -.21 & 14.44 & $<.001$ & .04 & .19 \\
\hline Mother anxiety & .18 & .07 & .16 & 7.19 & $<.01$ & .02 & .21 \\
\hline \multicolumn{8}{|l|}{ RIES Intrusion } \\
\hline Child exposure & .48 & .07 & .36 & 42.10 & $<.001$ & .16 & .16 \\
\hline Mother intrusion & .17 & .06 & .18 & 8.70 & $<.005$ & .05 & .21 \\
\hline Gender & -1.98 & .61 & -.18 & 10.60 & $<.005$ & .03 & .24 \\
\hline Mother anxiety & .06 & .02 & .14 & 4.98 & $<.05$ & .02 & .26 \\
\hline \multicolumn{8}{|l|}{ RIES Avoidance } \\
\hline Mother avoidance & .20 & .06 & .22 & 12.53 & $<.001$ & .05 & .05 \\
\hline Gender & -2.26 & .82 & -.17 & 7.55 & $<.01$ & .02 & .07 \\
\hline \multicolumn{8}{|l|}{ RIES Arousal } \\
\hline Child exposure & .42 & .09 & .29 & 22.91 & $<.001$ & .10 & .10 \\
\hline Mother arousal & .19 & .06 & .20 & 11.19 & $<.001$ & .04 & .14 \\
\hline Gender & -1.63 & .72 & -.14 & 5.14 & $<.05$ & .01 & .15 \\
\hline \multicolumn{8}{|l|}{ DSRS } \\
\hline Mother intrusion & .16 & .06 & .18 & 8.11 & $<.005$ & .07 & .07 \\
\hline Mother depression & .09 & .04 & .16 & 6.46 & $<.05$ & .03 & .10 \\
\hline Child exposure & .18 & .08 & .14 & 5.46 & $<.05$ & .02 & .12 \\
\hline \multicolumn{8}{|l|}{ RCMAS } \\
\hline Child exposure & .43 & .09 & .28 & 22.46 & $<.001$ & .10 & .10 \\
\hline Mother arousal & .24 & .06 & .23 & 15.90 & $<.001$ & .05 & .15 \\
\hline \multicolumn{8}{|l|}{ Brief Grief Scale } \\
\hline Mother anxiety & .03 & .01 & .17 & 6.64 & $<.05$ & .07 & .07 \\
\hline Child exposure & .10 & .03 & .20 & 12.17 & $<.001$ & .05 & .12 \\
\hline Mother intrusion & .06 & .02 & .16 & 6.43 & $<.05$ & .02 & .14 \\
\hline
\end{tabular}

B: raw regression coefficient; $\beta$ : standardised regression coefficient; $F: F$-test to enter a variable into the model

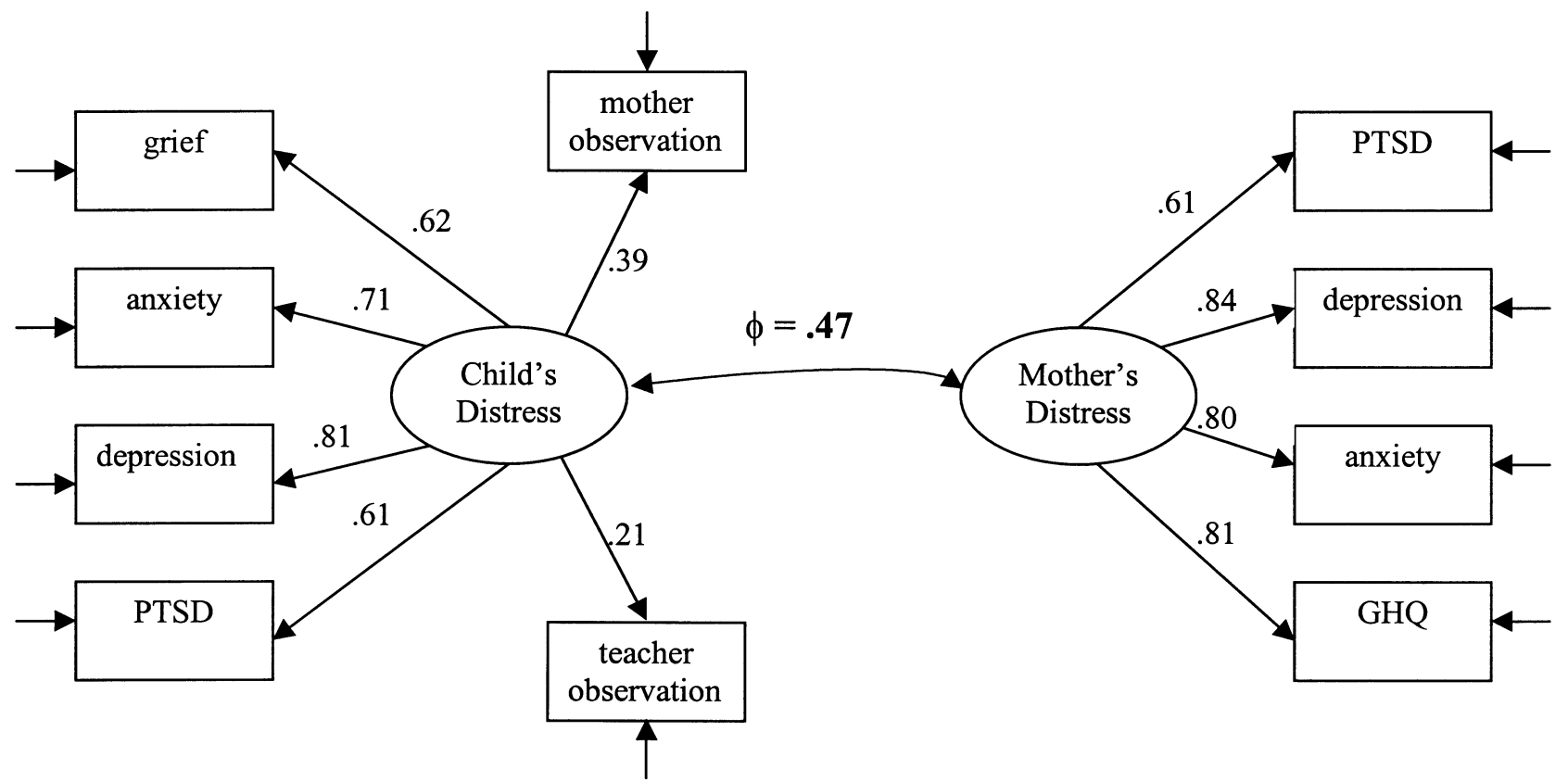

Figure 1. Measurement model; NFI $=.83, \chi^{2}(34)=242.7, p<.001$.

above 9 before the model can be considered to be a good fit.

\section{Measurement Model}

The measurement model is shown in Fig. 1. The child self-report measures and adult ratings of children are assumed to be fallible indicators of the child's true but unobserved distress. The variance of this latent variable was set to one. The loading linking each indicator to the factor is a measure of the association between the indicator and the factor; and the part of the indicator which is not explained by the factor is represented by an error term or residual. The variance of this error term 
Table 3

Structural Equation Model Parameter Estimates

\begin{tabular}{|c|c|c|c|c|c|c|}
\hline & & \multirow{2}{*}{$\frac{\begin{array}{c}\text { Measurement } \\
\text { model }\end{array}}{\text { (A) }}$} & \multirow{2}{*}{$\begin{array}{c}\begin{array}{c}\text { Final } \\
\text { model }\end{array} \\
(\mathrm{B})\end{array}$} & \multicolumn{3}{|c|}{ Structural models } \\
\hline & & & & (C) & (D) & (E) \\
\hline $\mathrm{MD} \leftarrow \mathrm{CD}$ & $\phi$ & .47 & .37 & .42 & .33 & .36 \\
\hline Exposure $\rightarrow$ CD & $\beta_{1}$ & & .37 & .36 & .26 & - \\
\hline Exposure $\rightarrow$ MD & $\beta_{2}$ & & .26 & .24 & - & .14 \\
\hline $\mathrm{M}$ Err $\leftarrow \mathrm{MD}$ & $\psi$ & & .59 & - & .57 & .58 \\
\hline T Err $\leftarrow$ Exposure & $\psi_{2}$ & & .15 & & & \\
\hline \multicolumn{7}{|l|}{ Child distress } \\
\hline Grief & $\lambda_{1}$ & .62 & .66 & .62 & .62 & .62 \\
\hline Anxiety & $\lambda_{2}$ & .71 & .63 & .70 & .69 & .70 \\
\hline Depression & $\lambda_{3}^{2}$ & .81 & .79 & .81 & .84 & .85 \\
\hline \multirow[t]{2}{*}{ Post-traumatic stress } & $\lambda_{4}$ & .61 & .64 & .62 & .60 & .61 \\
\hline & $\phi_{56}$ & & .21 & & & \\
\hline Teacher observations & $\lambda_{5}$ & .21 & .21 & .22 & .20 & .20 \\
\hline \multirow[t]{2}{*}{ Mother observations } & $\lambda_{6}$ & .39 & .31 & .38 & .26 & .32 \\
\hline & $\phi_{56}$ & & .11 & & & \\
\hline \multicolumn{7}{|l|}{ Mother distress } \\
\hline Post-traumatic stress & $\lambda_{7}$ & .61 & .64 & .61 & .62 & .62 \\
\hline Depression & $\lambda_{8}^{7}$ & .84 & .80 & .84 & .83 & .83 \\
\hline Anxiety & $\lambda_{9}^{8}$ & .80 & .75 & .80 & .80 & .80 \\
\hline GHQ & $\lambda_{10}$ & .81 & .84 & .81 & .82 & .82 \\
\hline & $\phi_{89}^{10}$ & & .24 & & & \\
\hline \multirow[t]{3}{*}{ Measures of fit } & $\chi^{2}(d f)$ & $242.7(34)$ & $102.3(37)$ & $265.9(42)$ & $156.9(42)$ & $167.9(42)$ \\
\hline & $p$ & $<.001$ & $<.001$ & $<.001$ & $<.001$ & $<.001$ \\
\hline & NFI & .83 & .93 & .82 & .89 & .89 \\
\hline
\end{tabular}

MD/CD; Mother/child distress; M Err/T Err: Mother/teacher residuals.

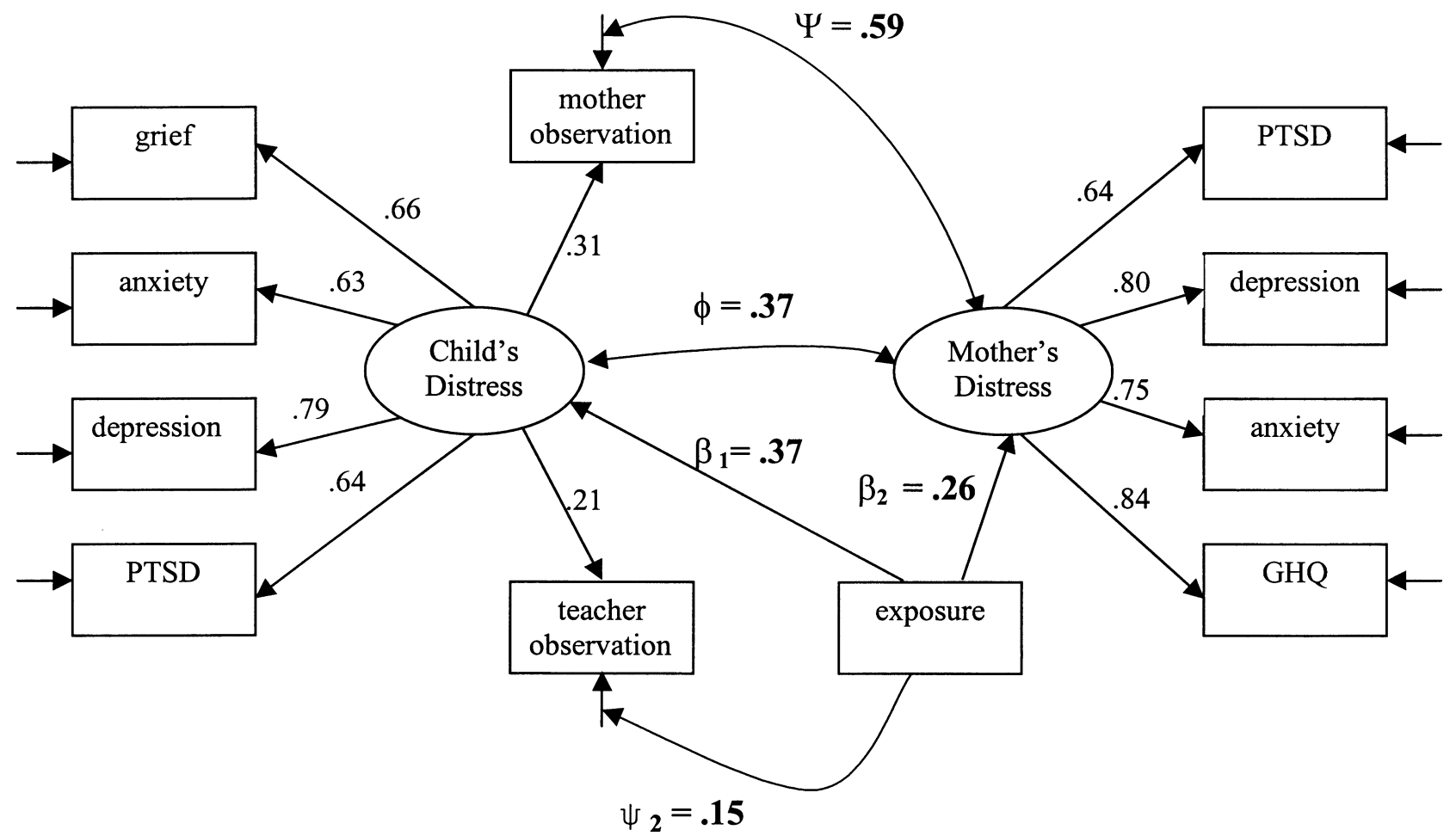

Figure 2. Final structural model; NFI $=.93, \chi^{2}(37)=102.37, p<.001$.

therefore represents the proportion of the variance of the indicator which is not accounted for by the factor. The latent variable of mother's distress was constructed in a similar way from the maternal self-report measures.

Fitting this measurement model, and regressing child's distress on mother's distress, gave high loadings for all self-report indicators of between .61 and .84 (Table 3 , column A); and moderate loadings for the mother's and teacher's Rutter questionnaires; but negligible loadings for the mother and teacher prosocial subscales $(-.04$ and -.03 respectively). The prosocial subscales were therefore excluded from the model. The standardised correlation coefficient between child distress and maternal distress is high $(\phi=.47)$. However, the model is a poor fit 
to the data, with an NFI of only .83, and a large and significant chi-squared statistic, $\chi^{2}(34)=242.7, p<.001$.

\section{Structural Models}

After constructing the measurement model, structural models were specified to define theoretically plausible patterns of associations between the variables. The best fitting structural model is shown in Fig. 2 (see Table 3, column B).

The standardised correlation coefficient between child distress and maternal distress is reduced $(\phi=.37)$. This is because the association between the two factors is now explained by additional theoretically plausible pathways which are specified in the model. The first of these additional pathways is between mother distress and the residuals to mother ratings, which is substantial $(\psi=$ .59). This is interpreted as meaning that mothers' rating errors are significantly associated with her own distress. The fit of a model where this linkage is excluded (Table 3, column C) is poor. The conclusion is that there is a substantial distorting effect of mother's own mental health on the ratings of her child.

The second of these additional pathways is between exposure and child and maternal mental health. As expected on the basis of previous analyses, exposure is significantly related to child distress $\left(\beta_{1}=.37\right)$ after controlling for the effects of maternal mental health on children. When this linkage is excluded (Table 3, column E), the model is a poor fit to the data. Child-reported exposure is also significantly related to maternal distress $\left(\beta_{2}=.26\right)$, and when this linkage is excluded, the NFI is reduced (Table 3 , column D).

In the final structural model, further theoretically driven relationships are specified. The effect of exposure on teacher ratings is quantified and controlled for using an equivalent strategy as was used to control for maternal rating bias: exposure correlates significantly with teacher rating residuals $\left(\psi_{2}=.15\right)$. There was also a small but significant association between mother and teacher rating residuals $\left(\phi_{56}=.11\right)$, and between anxiety and depression residuals for children $\left(\phi_{23}=.20\right)$ and mothers $\left(\phi_{89}=.24\right)$.

This final model represents a considerably better fit over the measurement model, with an NFI of .93 and a reduction in the $\chi^{2}$ statistic by 39.4 with 4 degrees of freedom $(p<.001)$ (see Table 3 , column B).

\section{Discussion}

It was predicted that: child exposure and distress across a broad band of measures would be high, and that distress would be associated with exposure; that child distress would also be associated with maternal mental health after controlling for the effects of exposure; and that mothers' ratings of their child would be influenced by their own psychological health.

It was found that children reported massive amounts of exposure to war stressors, and correspondingly high levels of PTSD symptoms. Using a cutoff score of 17 on the combined intrusion and avoidance subscales of the RIES (Dyregrov \& Yule, 1995) indicated that up to $58 \%$ would be likely cases, although conclusions about diagnosis are most tentative in the absence of individual clinical assessments. Children's self-reported levels of anxiety were, unexpectedly, lower than American normative data (Reynolds \& Richmond, 1978). Depressive feelings among the current sample of children were not markedly elevated compared to the best available normative data, and were, surprisingly, lower than the scores of children who survived a shipping accident. Normal peacetime prevalence of any psychiatric disturbance in 10 - and 11-year-olds was estimated by Rutter and colleagues (Rutter et al., 1970) to be $6.8 \%$; and for 14 - to 15 -year-olds it was $12.8 \%$. From their review of 38 international studies with differing methodologies, Verhulst and Koot (1992) found a median rate of $13 \%$ for children from 4 to 16 years for any disorder. In an earlier review, Gould, Wunsch-Hitzig, and Dohrenwend (1981) found a similar median prevalence rate of any disorder from 25 North American studies to be $11.8 \%$ across a similarly wide age range age. Inferences about caseness are limited in the present study due to lack of clinical interview follow-up, but by most conservative estimates levels of disturbance, estimated at between $18-22 \%$, are raised among children in Mostar.

Aspects of mothers' psychological health were measured in this study as putative mediating variables on child distress, but it is worth commenting briefly on the selfreported psychological health of mothers. Like their children, mothers reported high levels of PTSD symptoms. Again, due to lack of second wave follow-up, inferences about diagnosis must be limited, but the mean score of mothers on the RIES approached the best available cutoff for likely diagnosis of PTSD (Dyregrov \& Yule, 1995). Overall, depression among this group was not raised, but a sizeable minority of mothers (41/310; $13 \%$ ) obtained BDI scores that fell in the moderate to severely depressed range. Levels of anxiety were marginally elevated compared to American normative data (Spielberger et al., 1983). The estimated level of caseness from the GHQ of between $22-27 \%$ is marginally higher than estimates of $20-25 \%$ from a range of other community studies utilising the GHQ (e.g. see Burvill \& Knuiman, 1983); and higher than the more recent ECA study (see Robins \& Reiger, 1991) of $20 \%$ annual prevalence for any disorder in the U.S. Taken together, these results point to marginally raised levels of selfreported anxiety and depression, but the most striking finding is that, just as for children, only mothers' selfreports of post-traumatic stress are markedly high.

Of primary interest in the present study were risk and mediating factors on child distress. First, it was confirmed that exposure was significantly associated with all outcome measures. This is in line with previous studies that have found a relationship between war exposure and levels of children's distress (e.g. Macksoud, 1992; Kuterovac et al., 1994). The effect of exposure was greater for some measures (PTSD, anxiety) than others (depression), and while highly significant, the estimated amount of variance accounted for by exposure was modest $\left(\mathrm{R}^{2} \leqslant .16\right)$. Second, the predicted association between mother and child distress was also confirmed, in line with previous studies (e.g. Bryce et al., 1989; Dawes et al., 1989; Mghir et al., 1995). The relationship between exposure and distress remained significant in a series of regression equations where measures of mothers' mental health were included as possible explanatory variables. Different explanatory variables were retained as significant predictors for different child outcomes. So, for intrusion and arousal symptoms of PTSD and for anxiety, exposure was the best predictor, although there were also significant (and specific) effects of maternal mental health on these measures of outcome. In contrast, 
maternal mental health accounted for relatively more of the variance in children's self-reported depression: specifically, it was mothers' intrusion and depression scores that predicted child depression scores.

Aspects of this familial association were explored further using structural equation modeling. The joint effects of exposure and maternal mental health were confirmed in the best fitting model, and the size of the effects was the same $\left(\beta_{1}=\phi=.37\right)$. Modeling suggested that part of the association between mother and child distress was due to their shared exposure $\left(\beta_{1}\right.$ and $\left.\beta_{2}\right)$. Although only children's self-reported exposure was measured here, it was shown that this measure was related to mothers' distress. It is plausible that mothers and children experienced similar wartime events: we know that most of the children in this study were living with their parents at the time of assessment. Anecdotally, children were commonly separated from their fathers, who were drafted, but even those children who were ethnically cleansed tended to stay with mothers, to the extent that they accompanied their mothers to detention camps. Thus it is likely that the child's self-reported exposure is an indirect indicator of mother's exposure. Adults, like children, are affected by the amount and type of exposure, and mothers and children who experience similar events might be expected to react in very broadly similar ways.

After controlling for their shared exposure, there remained a significant and substantial relationship between mothers' and children's independent reports of their own distress $(\phi)$. In principle, this relationship might derive from shared wartime experiences not captured by the WTQ, from exposure to the same traumatic reminders (destroyed buildings, for example), from sharing the same living conditions, from similar learned coping styles, from shared familial vulnerability, and through a complex proximal interaction between children and mothers.

Such an interaction between children and mothers is likely to be bidirectional, and this was specified in the final structural equation model. In the case of PTSD, clinical evidence indicates that children and their parents may get locked into cycles of not talking about the event for fear of upsetting each other. In other words, mother and child negatively reinforce each other for avoiding processing their traumatic memories, and this is likely to maintain the symptoms of both. This is reflected in the relatively high correlations of mothers' and children's avoidance scores here. McFarlane (1987b) has reported on what may be a related measure of family interactions in families exposed to traumatic events in peacetime. He showed that such families are characterised by relatively more "irritable distress" (i.e. conflict and withdrawal) and maternal overprotection, and that this is directly related to child distress. It is also likely that mothers' general parenting skills are affected by their own psychological health: a distressed mother will likely be less available as a resource for her child. Conversely, distressed children will serve as an additional demand or stressor for mothers. Equally, parents serve as role models for their children (Pferferbaum, 1997), and if parents are coping poorly, their children are likely to fare less well, too.

Finally, obtaining independent data from children and mothers allowed important measurement issues to be addressed. In structural equation modelling, the construction of theoretically plausible latent variables enabled the examination of residual effects, or error terms. This was used here to examine and control for the effect of mothers' own distress on her ratings of her child. It was shown that the association between mother rating errors and her own distress was strong $(\psi=.59)$, and that this inflated the apparent effect of maternal distress on child distress: a clear and substantial distorting effect of mother's own distress on the rating of her child was found. Care must be taken in generalising from this finding, but it is consistent with previous studies using structural equation modelling techniques (e.g. Boyle \& Pickles, 1997; Fergusson et al., 1993) which have demonstrated a distorting effect of maternal mental healthspecifically, depression in mothers - on their ratings of children's behaviour. Current evidence for maternal bias in behaviour ratings of children illustrates the importance of obtaining data directly from children.

In summary, children in the present study reported massive amounts of exposure to war stressors and correspondingly high levels of PTSD symptoms and grief reactions. However, their levels of anxiety and depression were not elevated. Different sorts of risk factors operated for different outcomes. For PTSD symptoms and anxiety, exposure was the best predictor, and after controlling for exposure there was a significant effect of maternal mental health on the child. For child depression, maternal mental health was the best predictor, and after controlling for maternal mental health, there was a significant effect of exposure. Structural equation modelling suggested different pathways to account for this familial association, including shared exposure and complex family interactions.

Clinically, these data imply that large numbers of children may develop symptoms of PTSD after exposure to war. In that case, where many children are adversely affected, then large-scale community-based psychosocial programmes aimed at assisting them may be appropriate. The suggestion from the current work, which highlights the importance of family reactions in mediating children's distress, is that such programmes should include elements to address parents' needs and to support families, for example through educating families, fostering homeschool links, and setting up special support groups for parents. The implementation of large-scale, communitybased psychosocial programmes for children following war (Barton et al., 2000) and major disasters (e.g. Pynoos, Goenjian, \& Steinberg, 1998) have generally taken a public health approach, incorporating interventions at various levels in the community, including schools, youth centres, and clinics. Although the focus of such programmes differs from area to area, a common element is that of helping children to address and process their traumatic memories, whether that be in group treatments, individual and family work, or via school-based programmes.

In future research, there is a need to examine in more detail the putative risk and mediating factors which may influence the psychological health of children who have survived war. It will be informative in future studies to obtain a direct measurement of parental exposure, rather than relying on child exposure as a proxy measure. In a similar vein, more detailed measurement of exposure will allow researchers to model the effects of different types of exposure on children and parents. In addition, further data on pre-war factors (e.g. family and personal history, or prior exposure to stressful experiences) and post-war factors (e.g. coping styles, exposure to traumatic reminders) may be helpful in explaining and understanding children's psychological reactions to having lived through 
war and violence. Finally, there is a pressing need for further outcome studies to evaluate the effectiveness of community interventions for children following war.

\section{References}

Asarnow, J. R., \& Carlson, G. A. (1985). Depression Selfrating Scale: Utility with child psychiatric patients. Journal of Consulting and Clinical Psychology, 53, 491-499.

Barton, J., Puckering, C., Van Beinum, M., \& Parry-Jones, W. (2000). Psychosocial interventions for children in former Yugoslavia. Paper presented at the Fourth European Conference of the Association for Child Psychology and Psychiatry, London, January.

Beck, A. T., Rush, A. J., Shaw, B. F., \& Emery, G. (1979). Cognitive therapy of depression. New York: Guilford Press.

Beck, A. T., Steer, R. A., \& Garbin, M. G. (1988). Psychometric properties of the BDI: 25 years of research. Clinical Psychology Review, 8, 77-100.

Bentler, P. M. (1989). EQS: Structural equations manual. Los Angeles, CA: BMPD Statistical Software.

Birleson, P. (1981). The validity of depressive disorder in childhood and the development of a self-rating scale: A research report. Journal of Child Psychology and Psychiatry, 22, 73-88.

Birleson, P., Hudson, I., Buchanan, D. G., \& Wolff, S. (1987). Clinical evaluation of a self-rating scale for depressive disorder in childhood (Depression Self-rating Scale). Journal of Child Psychology and Psychiatry, 28, 43-60.

Boyle, M., \& Pickles, A. (1997). Influence of maternal depressive symptoms on ratings of child behaviour. Journal of Abnormal Child Psychology, 25, 399-412.

Bracken, B. A., \& Barona, A. (1991). State of the art procedures for translating, validating, and using psycho-educational tests in cross-cultural assessment. School Psychology International, 12, 119-132.

Bryce, J., Walker, N., Ghorayeb, F., \& Kanj, M. (1989). Life experiences, response styles, and mental health among mothers and children in Beirut, Lebanon. Social Science and Medicine, 28, 685-695.

Burvill, P. W., \& Knuiman, M. W. (1983). Which version of the GHQ should be used in community studies? Australian and New Zealand Journal of Psychiatry, 17, 237-242.

Cairns, E. (1996). Children and political violence. Oxford: Blackwell Publishers.

Carlson, E. B., \& Rosser-Hogan, R. (1994). Cross cultural responses to trauma: A study of traumatic experiences and post-traumatic symptoms in Cambodian refugees. Journal of Traumatic Stress, 7, 43-58.

Chimienti, G., Nasr, J., \& Khalifehi, L. (1989). Children's reactions to war related stress II: The influence of gender, age, and mother's reaction. International Journal of Mental Health, 21, 72-86.

Dawes, A., Tredoux, C., \& Feinstein, A. (1989). Political violence in South Africa: Some effects on children of the violent destruction of their community. International Journal of Mental Health, 18, 16-43.

Dyregrov, A., \& Raundalen, M., (1992). The impact of the Gulf war on the children of Iraq. Paper presented at the International Society for Traumatic Stress Studies World Conference, "Trauma and Tragedy", Amsterdam, June.

Dyregrov, A., \& Yule, W. (1995) Screening measures: The development of the UNICEF screening battery. Paper presented at the Fourth European Conference on Traumatic Stress, Paris, May.

Fergusson, D. M. (1997). Structural equation modeling in developmental research. Journal of Child Psychology and Psychiatry, 38, 877-887.

Fergusson, D. M., Lynskey, M. T., \& Horwood, L. J. (1993). The effects of maternal depression on maternal ratings of child behaviour. Journal of Abnormal Child Psychology, 21, 245-269.
Goldberg, D. P., \& Hillier, V. F. (1979). A scaled version of the General Health Questionnaire. Psychological Medicine, 9, 139-145.

Goldberg, D. P., \& Williams, P. (1988). A user's guide to the General Health Questionnaire. Windsor, U.K: NFERNelson.

Goodman, R. (1994). A modified version of the Rutter Parent Questionnaire including extra items on children's strengths: A research note. Journal of Child Psychology and Psychiatry, $35,1483-1494$.

Gould, M. S., Wunsch-Hitzig, R., \& Dohrenwend, B. (1981). Estimating the prevalence of childhood psychopathology. Journal of the American Academy of Child and Adolescent Psychiatry, 20, 462-476.

Gupta, L., Dyregrov, A., Gjestad, R., \& Mukanoheli, X. (1996). Trauma, exposure, and psychological reactions to genocide among Rwandan refugees. Paper presented at the 12th Annual Convention of the International Society for Traumatic Stress Studies, San Francisco, November.

Hacam, B., Smith, P., Yule, W., \& Perrin, S., (1998). Psychological services for children in war: Experiences in Mostar. Paper presented at the 14th International Congress of the International Association for Child and Adolescent Psychiatry and Allied Professions, Stockholm, November.

Horowitz, M. J., Wilner, N., \& Alvarez, W. (1979). Impact of event scale: A measure of subjective stress. Psychosomatic Medicine, 41, 209-218.

James, E. M., Reynolds, C. R., \& Dunbar, J. (1994). Selfreport instruments. In T. H. Ollendick, N. J. King, \& W. Yule (Eds.), International handbook of phobic and anxiety disorders in children and adolescents. New York: Plenum Press.

King, D. W., \& King, L. A. (1997). A brief introduction to structural equation modeling. PTSD Research Quarterly, 8, $1-4$.

Kinzie, J. D., Sack, W. H., Angell, R. H., \& Clarke, G. (1989). A 3-year follow-up of Cambodian young people traumatised as children. Journal of the American Academy of Child and Adolescent Psychiatry, 28, 501-504.

Kuterovac, G., Dyregrov, A., \& Stuvland, R. (1994). Children in war: A silent majority under stress. British Journal of Medical Psychology, 67, 363-375.

Macksoud, M. S. (1992). Assessing war trauma in children: A case study of Lebanese children. Journal of Refugee Studies, $5,1-15$.

Macksoud, M. S., \& Aber, J. L. (1996). The war experiences and psychosocial development of children in Lebanon. Child Development, 67, 70-88.

McFarlane, A. C. (1987a). Posttraumatic phenomena in a longitudinal study of children following a natural disaster. Journal of the American Academy of Child and Adolescent Psychiatry, 26, 764-769.

McFarlane, A. C. (1987b). Family functioning and overprotection following a natural disaster: The longitudinal effects of post-traumatic morbidity. Australia and New Zealand Journal of Psychiatry, 21, 210-218.

Mghir, R., Freed, W., Raskin, A., \& Katon, W. (1995). Depression and post traumatic stress disorder among a community sample of adolescent and young adult Afghan refugees. Journal of Nervous and Mental Disease, 183, 24-30.

Nader, K., Pynoos, R. S., Fairbanks, L., Al-Ajeel, M., \& AlAsfour, A. (1993). A preliminary study of PTSD and grief among the children of Kuwait following the Gulf crisis. British Journal of Clinical Psychology, 32, 407-416.

Pfefferbaum, B. (1997). Posttraumatic stress disorder in children-a review of the past 10 years. Journal of the American Academy of Child and Adolescent Psychiatry, 36, 1503-1511.

Pynoos, R. S., Goenjian, A. K., \& Steinberg, A. M. (1998). A public mental health approach to the postdisaster treatment of children and adolescents. Child and Adolescent Psychiatric Clinics of North America, 7, 195-210. 
Reynolds, C. R. (1980). Concurrent validity of What I Think and Feel: The Revised Children's Manifest Anxiety Scale. Journal of Consulting and Clinical Psychology, 48, 774-775.

Reynolds, C. R., \& Richmond, B. O. (1978). What I think and feel: A revised measure of children's manifest anxiety. Journal of Abnormal Child Psychology, 6, 271-280.

Richman, N., Ratilal, A., \& Aly, A. (1989). The psychological effects of war on Mozambican children. Maputo, Mozambique: Ministry of Education.

Robins, L., \& Reiger, D. A. (1991). Psychiatric disorders in America: The epidemiologic catchment area study. New York: Free Press.

Rutter, M. (1967). A children's behaviour questionnaire for completion by teachers: Preliminary findings. Journal of Child Psychology and Psychiatry, 8, 1-11.

Rutter, M., Tizard, J., \& Whitmore, K. (1970). Education, health, and behaviour. London: Longmans.

Saigh, P. A. (1991). The development of posttraumatic stress disorder following four different types of traumatization. Behavior Research and Therapy, 29, 213-216.

Smith, P. A., Perrin, S., Yule, W., Hacam, B., \& Stuvland, R. (2000). War exposure and children from Bosnia-Hercegovina:
Psychological adjustment in a community sample. Manuscript submitted for publication.

Spielberger, C. D., Gorsuch, R. L., Luschene, R. E., Vagg, P. R., \& Jacobs, G. A. (1983). Manual for the State-Trait Anxiety Inventory. Palo Alto, CA: Consulting Psychologists Press.

SPSS. (1993). Base system user's guide: Release 6.0. Chicago: SPSS Inc.

UNICEF. (1994). Mostar: Situational analysis. Sarajevo: Author.

Verhulst, F. C., \& Koot, H. M. (1992). Child psychiatric epidemiology - concepts, methods and findings. London: Sage Publications.

Yule, W. (1998). Anxiety, depression, and post-traumatic stress disorder in children. In I. Sclare (Ed.), The NFER child portfolio. Windsor, U.K.: NFER-Nelson.

Zivcic, I. (1993). Emotional reactions of children to war stress in Croatia. Journal of the American Academy of Child and Adolescent Psychiatry, 32, 709-713.

Manuscript accepted 16 August 2000 